\title{
Phenindione sensitivity with leukaemoid reaction and hepato-renal damage
}

\author{
J. S. WRIGHT \\ M.B., M.R.C.P. \\ Medical Registrar, Liverpool Royal Infirmary
}

SOUlier \& GUEguen, who first introduced phenindione as a therapeutic agent, were also the first to record sensitivity to the drug (Soulier \& Gueguen, 1947). Perkins (1962a) reviewed 132 cases of sensitivity reaction of which six had been fatal. Since this time further severe reactions have been reported with a significant number of fatalities. The incidence of toxic reactions is variously reported. Perkins found an incidence of $5 \%$. Other estimates have varied from as low as $0.1 \%$ (Ager \& Ingram, 1957) to as high as $10.7 \%$ (Stafford, 1961), and in a recent trial of short term anticoagulants (Report to Medical Research Council, 1969) sixteen of 712 patients on full therapeutic dosage of phenindione showed definite or possible sensitivity reactions, an incidence of $2.25 \%$ within a period of 28 days. It is of interest that none of the patients on the control low-dosage regimen showed toxic signs, and there seems to be a relationship between higher dosages and toxic reactions, perhaps favouring the view that some of the adverse effects of phenindione are the direct result of a potentially toxic modified benzene ring in the compound (Burns \& Desmond, 1958).

From time to time pleas have appeared for the abandonment of phenindione in favour of the coumarin derivatives (Brown \& McMillan, 1954; Tait, 1960; Shapiro, 1962; Hollman \& Wong, 1964; Davies, 1965; British Medical Journal, 1969). Nevertheless it remains a popular anticoagulant in this country, and in reporting this severe sensitivity reaction, it is hoped to draw attention again to its hazards.

\section{Case report}

A 26-year-old Nigerian woman, 4 years resident in England, developed a deep vein thrombosis following Caesarean section. After 10 days' heparin therapy, phenindione was commenced and continued on an out-patient basis with thrice weekly estimations of prothrombin time. The dose ranged from 150 to $300 \mathrm{mg}$ daily with an average daily dose of $200 \mathrm{mg}$ and a total dose of $3.8 \mathrm{~g}$. After 4 weeks she was re-admitted with a history of sweats and

Present address: Senior Registrar, Liverpool Regional Cardiac Centre, Sefton General Hospital, Smithdown Road, Liverpool, 15. rigors for 10 days, several episodes of haemoptysis and haematuria, a generalized pruritus, sore throat, pain in the right upper quadrant of the abdomen and right loin, and vomiting. On examination she was icteric with a pyrexia of $104^{\circ} \mathrm{F}\left(40^{\circ} \mathrm{C}\right)$. There was a generalized raised, pruritic eruption, enlarged, tender lymph nodes in the neck and axillae, a pharyngotonsillitis and a tender hepatomegaly to 2 in. below the costal margin. Pelvic examination was negative. Chest X-ray and screening of the diaphragm was normal. The urine was heavily blood-stained and contained bilirubin, but culture was negative. The haemoglobin was $90 \%$, white blood cells 11,000 with normal differential count. Prothrombin time was $55 \mathrm{sec}$ (control $15 \mathrm{sec}$, concentration $28 \%$ ). A throat swab produced monilia, and blood cultures were negative. Examination for malarial parasites, $\mathrm{HbS}, \mathrm{HbH}$ and G-6-P-D deficiency, were all negative. Serum bilirubin was $7.7 \mathrm{mg} \%$, SGPT 308 Karmen units, Alk. Phos. 13.7 KA units. Serum albumin $3 \cdot 7$, globulin $2 \cdot 1 \mathrm{mg} / 100 \mathrm{ml}$.

Phenindione was discontinued, but the jaundice deepened, and on the fifth day after admission the patient vomited an Ascaris worm. She became extremely weak, scarcely able to lift an arm. Sacral and periorbital oedema developed, and the skin began to desquamate. There was a continued fever, a tachycardia and a persistent hypotension of $90 / 50$ $\mathrm{mmHg}$. By the tenth day of hospitalization there was clouding of consciousness, and a hepatic-precoma regime was instituted, with neomycin both orally and by enemata, total exclusion of protein, and an intravenous infusion of $25 \%$ dextrose. At this stage the bilirubin was $17 \mathrm{mg} / 100 \mathrm{ml}$ (direct 3.5 , indirect 13.5 ), the serum albumin had fallen to $1.6 \mathrm{~g} / 100 \mathrm{ml}$ with a globulin of 5.9 and gamma globulin of 3.5. The alkaline phosphatase was 27 KA units, thymol turbidity 14, SGPT 410 Karmen units, $\mathrm{Hb} 60 \%$. The white blood cells had risen dramatically to 47,000 , with polymorphonuclear reaction, increased primitives and $2 \%$ plasma cells. The marrow was active but normal. ESR was 120 $\mathrm{mm} / \mathrm{hr}$. The serum $\mathrm{Na}$ was $117, \mathrm{~K} \mathrm{4} 6, \mathrm{Cl} 81$, Alk Res $18 \mathrm{mEq} / \mathrm{l}$, urea $30 \mathrm{mg} / 100 \mathrm{ml}$.

Examination of stools for cysts and ova was repeatedly negative but the Ascaris had brought into 
consideration the possibility of a pyogenic hepatitis, and for this reason antibiotic therapy was commenced with ampicillin and cephaloridine, and continued for the next 18 days, without effect on the fever.

Over the third and fourth weeks of hospitalization there was a gradual improvement in liver function, the bilirubin dropped, the serum albumin rose, the serum sodium rose without specific replacement, and the liver became less tender. At the same time the leukaemoid white count gradually fell to normal. However, she remained ill; the pyrexia and lymphadenopathy persisted, and there was widespread desquamation of skin, that of the soles of the feet falling away like casts. The haemoglobin fell to $58 \%$, MCHC $33 \%$, reticulocytes $2.8 \%$, Coombs' negative, faecal occult blood negative.

Albumin and casts in large numbers began to appear in the urine, and the blood urea rose to 58 $\mathrm{mg} / 100 \mathrm{ml}$. The creatinine clearance was $25 \mathrm{ml} / \mathrm{min}$. The urinary findings were persistent over the next few days, and in the fifth week of hospitalization, corticosteroid therapy was instituted with prednisolone in a dose of $60 \mathrm{mg}$ daily. The temperature fell to normal over the next $24 \mathrm{hr}$, and there was a striking increase in appetite and general well-being. After 5 days she became ambulant. The albuminuria and casts cleared, and the haemoglobin rose to $81 \%$ without haematinics.

Seven weeks after withdrawal of phenindione however the blood urea was $73 \mathrm{mg} / 100 \mathrm{ml}$, the creatinine clearance $30 \mathrm{ml} / \mathrm{min}$, but over the next 4 weeks the blood urea fell to $26 \mathrm{mg} / 100 \mathrm{ml}$. Apart from evanescent skin rashes and some alopecia areata the patient remained symptom-free during this period while the prednisolone was gradually withdrawn.

\section{Discussion}

Skin

A rash is the commonest form of sensitivity reaction to phenindione. Usually erythematous, it may be scarlatiniform, papular or urticarial. Petechial haemorrhages occur on the legs and the palate, and do not necessarily reflect over-dosage (Jones, 1960; Perkins, 1962a; Makous \& Vander Veer, 1954). Necrotic eruptions occur and gangrene has been described (Keyrilainen, 1958; Kipen, 1961; Desai, 1967; Larcan, Bertrand \& Richon, 1968). In the present case the rash appeared urticarial, but was followed by an unusually severe desquamation, a feature also of nine of the 130 cases reviewed by Perkins (1962a). Exfoliative dermatitis has been described in six cases, one of which was fatal (Garnett et al., 1962). An eczematous reaction may occur (Smith, 1965; Copeman, 1965), and it has been suggested that this type of reaction particularly may presage more serious generalized effects (Copeman, 1968).

\section{Pyrexia}

Fever is probably next in order of frequency, and has been regarded as an important early sign of toxicity (Perkins, 1962a). The present case is unusual in the persistence of fever for nearly 5 weeks after withdrawal of phenindione, and its rapid disappearance with corticosteroid therapy.

\section{Liver}

Phenindione jaundice is a well recognized entity and typically occurs about the fifth week of treatment, though in one case (Heine, 1962) it occurred after a second course of treatment. At least fifteen cases are well recorded. Most have presented a cholestatic picture (Burns \& Desmond, 1958; Wallace, 1960), but some have shown a significant degree of hepatocellular damage (Makous \& Vander Veer, 1954; East \& Beamish, 1957; Perkins, 1962b; Baker \& Williams, 1963; Mohamed, 1965) and in some the picture has been mixed. Four cases have been fatal, but two were associated with agranulocytosis (Kirkeby, 1954; Burns \& Desmond, 1958), one with nephropathy (Turiaf, 1965) and one with oliguric renal failure (Smith, 1965). The degree of hepatocellular damage in the present case seems to be unusually severe, the serum albumin dropping to $1.6 \mathrm{~g} / 100 \mathrm{ml}$, the bilirubin rising to $17 \mathrm{mg} / 100 \mathrm{ml}$; though in the case described by Makous \& Vander Veer (1954) the bilirubin rose to 14 with a high thymol turbidity.

\section{Kidney}

The phenindione nephropathy tends to be rather more severe than the hepatitis. Galea, Young \& Bell (1963) in reviewing the literature found five cases, three of them fatal, and added another fatality. A further fourteen cases have been reported (Pearce, 1963; Baker \& Williams, 1963; Hollman \& Wong, 1964; Follett, 1964; Lee \& Holden, 1964; Smith, 1965; Davies, 1965, Copeman, 1965; Turiaf, 1965; Chauvin, 1965), four of them fatal. The six cases described by Smith presented as oliguric renal failure; biopsies were carried out in four and all showed some degree of tubular necrosis. Two showed an interstitial nephritis, as did the cases of Baker \& Williams, Galea et al., and a case described at the Postgraduate Medical School (1960). Other cases have presented as a nephrotic syndrome or simply as albuminuria with a raised blood urea as in the present case. As in phenindione jaundice the signs may appear after withdrawal of the drug for other reasons. This was the case here. There is a suggestion that renal damage may be permanent (Smith, 1965; Baker \& Williams, 1963; Davies, 1965), and in the present case the azotaemia was certainly prolonged. Of the cases described with hepatitis and nephropathy combined, one was fatal (Turiaf, 1965), the 
other, as in the present case, responded well to corticosteroids (Baker \& Williams, 1963).

\section{Blood}

It was the development of fatal agranulocytosis in two out of 261 patients on phenindione in a trial of four anticoagulants (Brown \& McMillan, 1954), which led to its unpopularity in North America, and Perkins found eighteen cases of granulocytopenia, ten of which progressed to agranulocytosis, fatal in five cases. Further cases have been described since (Metzger, 1963; Malinvaud, Leobardy \& Suchaud, 1966). Recovery is to be hoped for on withdrawal of the drug, and institution of steroid and antibiotic therapy. Thrombocytopenia has been described (Farwell, 1959; Bingle \& Shine, 1959), and, as in the present case, anaemia (Makous \& Vander Veer, 1954; Burns \& Desmond, 1958). Mohamed (1965) reported pancytopenia with a white blood count of 800 and a normal marrow and negative Coombs' test. The leukaemoid reaction seen in the present case seems a rare response, and the white count of 47,000 unique. Only one reference to leukamoid reaction in phenindione sensitivity could be found (Makous \& Vander Veer, 1954). Though the white count in that case was only 24,700 , it had other features in common with the present case, in the presence of plasma cells, a severe hepatocellular reaction, and in the fact that their patient also was a Negro woman.

\section{Other manifestations}

A lymphadenopathy is well recorded, though uncommon. It was a prominent feature of the present case, as was a stomatitis, which may be ulcerative (Perkins, 1962a; Hollman \& Wong, 1964). Paralytic ileus has been ascribed to phenindione (Menon, 1966; Nash, 1966). Diarrhoea is common, steatorrhoea less so. A bloody dysentery was described by Juel-Jensen (1959), and haemorrhagic ulcerative colitis by Tanser \& Keat (1966).

A fatal myocarditis has been described (Kerwin, 1964) and recently a neuropathy (Mehotra, 1967).

This brief survey has been concerned only with the non-haemorrhagic complications of phenindione therapy. The benefits of long-term anticoagulant therapy must often be in doubt, and the risk of haemorrhage always present and perhaps as high as $10 \%$ in in-patients, $33 \%$ in out-patients (Zweifler, Coon \& Willis, 1966). It is hardly justifiable to add the risk of serious toxic reaction when less toxic alternative drugs are available. Fever and skin rashes often presage more serious reactions, and, although it has been stated that minor reactions can be ignored (Menon, 1968), the author feels that these should be regarded as an indication for immediate change to a coumarin derivative. This change the author has usually made by substituting $3 \mathrm{mg}$ warfarin for each $50 \mathrm{mg}$ phenindione without pause in treatment and with frequent prothrombin estimations and dosage adjustment over the ensuing 2 weeks. Patients who have shown 'phenindione resistance' may require a much lower dose of warfarin.

\section{Acknowledgments}

I wish to thank Mrs W. J. A. Francis for her permission to publish this case, and $\operatorname{Dr} \mathrm{C}$. M. Ogilvie for his advice and encouragement.

\section{References}

Ager, J.A.M. \& INGram, G.I.C. (1957) Agranulocytosis during phenindione therapy. British Medical Journal, 1, 1102.

BaKeR, S.B. DE C. \& Williams, R.T. (1963) Acute interstitial nephritis due to drug sensitivity. British Medical Journal, 1, 1655.

Bingle, J. \& Shine, I. (1959) Phenindione sensitivity. Lancet, ii, 377.

British Medical Journal (1969) Today's drugs. Anticoagulant Drugs, 1, 365.

Brown, K.W.G. \& McMillan, R.L. (1954) Choice of an anticoagulant. American Journal of Medical Science, 227, 526.

Burns, C. \& Desmond, F.B. (1958) Sensitivity to dindevan (phenylindanedione). Report of a case with a review of the literature. New Zealand Medical Journal, 57, 283.

Chauvin, H. (1965) La prévention des phlébites postopératoires après prostatectomie. Journal d'urologie et de néphrologie, 71, 239.

Copeman, C.W. (1965) Phenindione toxicity. British Medical Journal, 2, 305.

Copeman, C.W. (1968) Side-effects of phenindione. British Medical Journal, 3, 557.

Davies, D. (1965) Phenindione sensitivity. British Medical Journal, 2, 231.

DESAI, S.N. (1967). Extensive skin necrosis following anticoagulant therapy. British Journal of Plastic Surgery, 20, 325 .

EAST, E.N. \& BEAMISH, R.E. (1957) Severe sensitivity reaction (hepatitis, dermatitis and pyrexia) attributable to phenylindanedione. Canadian Medical Association Journal, 77, 1028.

FARWELL, C. (1959) Thrombocytopenia due to phenindione (Hedulin) sensitivity; report of a case. Medical Annals of the District of Columbia, 28, 82.

FolletT, S.A. (1964) Oliguria due to a hypersensitivity reaction to phenindione. Nursing Times, 60, 1420.

Galea, E.G., Young, L.N. \& Bell, J.R. (1963) Fatal nephropathy due to phenindione sensitivity. Lancet, i, 920.

Garnett, E.S., Pegrum, G.D. \& McDonald, S.J. (1962) A fatal case of phenindione sensitivity. British Medical Journal, 2, 1032.

Heine, B.E. (1962) Phenindione jaundice. Lancet, i, 489.

Hollman, A. \& Wong, H.O. (1964) Phenindione sensitivity. British Medical Journal, 2, 730.

JoNES, N.L. (1960) Hepatitis due to phenindione sensitivity. British Medical Journal, 2, 504.

Juel-Jensen, B.E. (1959) Sensitivity to phenindione. A case of severe diarrhoea. British Medical Journal, 2, 173.

KERWIN, A.J. (1964) Fatal myocarditis due to sensitivity to phenindione. Canadian Medical Association Journal, 90, 1418. 
Keyrilainen, O. (1958) Haemorrhagic cutaneous necrosis from phenylindanedione. Nordisk Medicin, 59, 567.

KIPEN, C.S. (1961) Gangrene of the breast-a complication of anticoagulant therapy. Report of two cases. New England Journal of Medicine, 265, 638.

Kirkeby, K. (1954) Agranulocytosis following treatment with phenylindanedione. Lancet, ii, 580.

Larcan, A., Bertrand, P. \& Richon, J. (1968) Accidents Cutanés Nécrotico-bulleux dus aux antivitamines $K$. Presse Médicale, 76, 1217.

Lee, H.A. \& Holden, C.E. (1964) Phenindione nephropathy with recovery: studies of morphology and renal function. Postgraduate Medical Journal, 40, 327.

Malinvaud, G., Leobardy, J. De \& Suchaud, C. (1966) Agranulocytosis survenue au cours d'un traitement par phenyl-indane-dione. Presse Médicale, 74, 18458.

Makous, N. \& VANDer Veer, J.B. (1954) Severe drug reaction to phenindione (Phenylindanedione). Journal of the American Medical Association, 155, 739.

Mehotra, T.N. (1967) Phenindione induced neuropathy. British Medical Journal, 3, 218.

Menon, I.S. (1966) Phenindione and paralytic ileus. Lancet, i, 1421.

Menon, I.S. (1968) Side effects of phenindione. British Medical Journal, 2, 622.

Metzger, H., Spruch, M. \& Fornoff, H. (1963) Agranulocytose et thrombopénie provoquées par la pindione. Nouvelle revue Française d'hématologie, 3, 603.

MoHAMED, S.D. (1965) Sensitivity reaction to phenindione, with urticaria, hepatitis and pancytopenia. British Medical Journal, 2, 1475.

Nash, A.G. (1966) Phenindione and paralytic ileus. Lancet, ii, 51 .
Pearce, J.M. (1963) Nephropathy and phenindione sensitivity. Lancet, i, 1158.

Perkins, J. (1962a) Phenindione sensitivity. Lancet, i, 127.

Perkins, J. (1962b) Phenindione jaundice. Lancet, i, 125.

Postgraduate Medical School of London (1960) A case of pulmonary hypertension. British Medical Journal, 2 , 1219.

Report to the Medical Research Council (1969) Report of short-term anticoagulant administration after myocardial infarction. British Medical Journal, 1, 335.

ShapIRo, S. (1962) Reactions with phenindione. Lancet, ii, 52.

Sмiтh, K. (1965) Acute renal failure in phenindione sensitivity. British Medical Journal, 2, 24.

SOULIER, J.P. \& GUEGUEN, J. (1947) Action hypoprothrombinémiante (anti-K) de la phényl-indane-dione étudiée expérimentalement chez le lapin: son application chez l'homme. Comptes rendus des séances de la Société de biologie et de filiales, 141, 100.

STAFFORD, J.L. (1961) Symposium on Anticuagulant Therapy. (Ed. by Sil George Pickering). F'. 186. Harvey \& Blythe, London.

TAIT, G.B. (1960) Nephropathy during phenindione therapy. Lancet, ii, 1198.

TANSer, A.R. \& Keat, E.C.B. (1966) Phenindione-induced haemorrhagic ulcerative colitis. British Medical Journal, $1,588$.

Turiaf, J. (1965) Hépatonéphrite aigue mortelle due au phenylindanedione. Bulletins et Memoires de la Société Médicale des Hopitaux de Paris, 116, 9.

WallaCe, D.C. (1960) Sensitivity to phenindione: (Dindevan): Report of two cases. Medical Journal of Australia, 47, 934.

Zweifler, A.J., Coon, W.W. \& Willis, P.W. (1966) Bleeding during oral anticoagulant therapy. American Heart Journal, 71, 118.

\title{
Hypervitaminosis D, anaemia and renal failure
}

\author{
ROGER GABRIEL \\ M.B., M.R.C.P., D.C.H. \\ Medical Registrar
}

\author{
A. M. JOEKES \\ M.A., B.M., F.R.C.P. \\ Physician and Senior Lecturer
}

Institute of Urology, St Philip's Hospital, St Peter's Hospital Group, London, W.C.2

\author{
E. ORTON \\ M.A., B.M., B.Ch.
}

General Practitioner, 98 Harley Street, London, W.1

A 53-year-old English lady was referred in January 1967 because of reduction in renal function. The only symptom disclosed was an invariable nocturia and daytime frequency of micturition every 2 to $3 \mathrm{hr}$ during the previous year. The past history included an 18 month history of variable anaemia of 7-10 $\mathrm{g} / 100 \mathrm{ml}$ (Table 1), unexplained by barium meals, gastroscopy and laparotomy. Study of the bone marrow in June 1966 showed normal cellularity, erythropoiesis was normoblastic with normal haemoglobinization; $10 \%$ of the white cell precursors were developing eosinophils. There had been no sustained response to iron, vitamin $B_{12}$ or folic acid.

On examination: no abnormality; BP 130/80; height $5 \mathrm{ft} 4$ in $(160 \mathrm{~cm})$; weight $47 \mathrm{~kg}$.

Random and early morning urines were normal save for a specific gravity not exceeding 1010 . Haemoglobin $8.8 \mathrm{~g} / 100 \mathrm{ml}$; red blood count $3 \cdot 1$

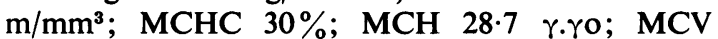
$96.7 \mathrm{cu} \mu$; reticulocytes $3.5 \%$; serum iron $105 \mu \mathrm{g} / 100$ $\mathrm{ml}$; total iron binding capacity $270 \mu \mathrm{g} / 100 \mathrm{ml}$; white 